\title{
Utility of fasting plasma glucose test as screening tool for gestational diabetes mellitus based on International Association of the Diabetes and Pregnancy Study Group criteria
}

\author{
Amita Sharma*, Alpana Agrawal, Manisha Goel, Manisha Gupta
}

Department of Obstetrics and Gynecology, Santosh Medical College, Ghaziabad, UP, India

Received: 22 April 2016

Accepted: 16 May 2016

*Correspondence:

Dr. Amita Sharma,

E-mail: amitakaushal@yahoo.co.in

Copyright: (c) the author(s), publisher and licensee Medip Academy. This is an open-access article distributed under the terms of the Creative Commons Attribution Non-Commercial License, which permits unrestricted non-commercial use, distribution, and reproduction in any medium, provided the original work is properly cited.

\section{ABSTRACT}

Background: The International Association of Diabetes and Pregnancy Study Groups (IADPSG) criteria have recently been endorsed by various bodies for screening and diagnosing Gestational Diabetes (GDM). The present study was done to diagnose gestational diabetes (GDM) by the International Association of Diabetes and Pregnancy Study Groups (IADPSG) criteria in a North Indian Population and to evaluate the performance of fasting plasma glucose (FPG) in screening and diagnosis of GDM.

Methods: We conducted a prospective observational study on 417 pregnant women. The women were screened for GDM between 24 weeks and 28 weeks of gestation by 75 -g oral glucose tolerance test (OGTT) and GDM diagnosed by the IADPSG criteria.

Results: The prevalence of GDM was 17.7\% [95\% Confidence interval (CI) $21.4-14.1 \%$ ] using the IADPSG criteria. Amongst the women diagnosed to have GDM, 64.9\% had abnormal fasting plasma glucose (FPG). FPG cut-off value of $92 \mathrm{mg} / \mathrm{dL}$ identified $11.5 \%$ pregnant women with GDM. FPG cut-off value of $80 \mathrm{mg} / \mathrm{dL}$ ruled out GDM in $54.7 \%$ women. If $80 \mathrm{mg} / \mathrm{dL}$ were made the cut point to decide who should have the 75 -g OGTT, then $56.8 \%$ (45.3\% with values $<4.4 \mathrm{mmol} / \mathrm{L}$ plus $11.5 \%$ with value $>5.1 \mathrm{mmol} / \mathrm{L}$ ) of pregnant women could avoid the $75-\mathrm{g}$ OGTT with the probability that $1.9 \%$ of patients with GDM may be missed.

Conclusions: FPG at 24-28 weeks' gestation could be used as a screening test to identify GDM patients. Women with an FPG between $\geq 80 \mathrm{mg} / \mathrm{dL}$ and $\leq 92 \mathrm{mg} / \mathrm{dL}$ would require a 75-g OGTT to diagnose GDM.

Keywords: GDM, IADPSG Criteria, FPG, Screening, Pregnancy

\section{INTRODUCTION}

Gestational diabetes mellitus (GDM) was earlier defined as "hyperglycaemia first recognized during pregnancy" and has more recently (2015) been described by the American Diabetes Association (ADA) as "Diabetes diagnosed in the second or third trimester of pregnancy that is not clearly overt diabetes". Untreated GDM results in poor maternal and fetal outcomes: women with GDM are more likely to suffer preeclampsia, operative delivery and stillbirth, and infants are at higher risk of preterm delivery and macrosomia or large for gestational age (LGA), which is associated with birth injury, respiratory distress and neonatal hypoglycaemia. In the longer term, children born to mothers with GDM are at greater risk of obesity and type 2 diabetes in later life, a phenomenon attributed to the effects of intrauterine exposure to hyperglycaemia. ${ }^{2}$

The work of Crowther et al and Landon et al showed that treatment of GDM reduced perinatal complications, and this has finally led to the acceptance of the need to screen and treat GDM. ${ }^{3,4}$

The Hyperglycaemia and Adverse Pregnancy Outcome (HAPO) Study, one of the largest studies ever done on 
GDM, showed a continuum of risk between maternal glucose levels and adverse pregnancy outcomes. The HAPO Study used a 2-h 75-g glucose test as single-step screening and diagnostic test. ${ }^{5}$ Based on this study, the International Association of Diabetes and Pregnancy Study Groups (IADPSG) criteria for GDM were developed. ${ }^{6}$ For the IADPSG criteria, an OGTT is done in the fasting state using $75 \mathrm{~g}$ of glucose at 24-28 weeks, and GDM is diagnosed if any one of the following cutpoints is met, i.e., fasting $\geq 92 \mathrm{mg} / \mathrm{dl}$, or $1 \mathrm{hr} \geq 180 \mathrm{mg} / \mathrm{dl}$ or $2 \mathrm{hr} \geq 153 \mathrm{mg} / \mathrm{dl}$. The strength of the one - step IADPSG criteria include a reduction in the patient burden by using a test of only 2-h duration and dispensing with a preliminary glucose challenge test a test chosen more for its convenience in a crowded clinic rather than for its relation to patient care. The IADPSG has proposed the elimination of a screening test in favour of proceeding directly to a diagnostic test for GDM.

Among the collaborating centres in the HAPO study, the prevalence rates of GDM differed widely, varying from 9 to $25.5 \% .^{7}$ Indian women were not represented in the HAPO cohort. It is important to note that, for the complete HAPO cohort, the IADPSG criteria diagnosed $55 \%$ on the fasting glucose alone. ${ }^{7}$ On the basis of the initial IADPSG recommendations, consideration has been given to a simplification of the testing procedure, with for example, the use of only the fasting or the fasting and the 1-h sample.

The WINGS (Women in India with GDM Strategy) study from Chennai, India showed that the Diabetes in Pregnancy Study Group of India (DIPSI) nonfasting OGTT criteria had a very low sensitivity (27.7\%) compared to the WHO (1999) criteria and even lower in comparison with the IADPSG criteria $(22.6 \%)$, although, the specificity was quite high. ${ }^{8}$

The IADPSG criteria increased GDM prevalence nearly three-fold in a study by Agarwal et al. ${ }^{9}$ They questioned the helpfulness of the full 2-h oral glucose tolerance test (OGTT), as recommended by the International Association of the Diabetes and Pregnancy Study Groups (IADPSG) for the diagnosis of gestational diabetes mellitus (GDM). Agarwal et al. suggest an FPG $\geq 5.1 \mathrm{mmol} / 1$-based diagnosis of GDM and a defined FPG $<4.4 \mathrm{mmol} / \mathrm{l}$ to exclude GDM; women meeting these criteria would therefore not require OGTT. According to this approach, the number of OGTTs would be cut by $50.6 \%$. A meta-analysis also reported that a fasting plasma glucose level (at a threshold of $4.7 \mathrm{mmol} / \mathrm{L}$ [85 $\mathrm{mg} / \mathrm{dL}]$ ) by 24 weeks gestation are good at identifying women who do not have GDM. ${ }^{10}$

The initial FPG-by significantly reducing the number of cumbersome OGTTs needed-can make the IADPSG recommendations more acceptable worldwide. The utility of FPG, to screen GDM, requires further investigation in our settings. The objective of the present prospective observational study was to diagnose gestational diabetes
(GDM) by the International Association of Diabetes and Pregnancy Study Groups (IADPSG) criteria in a North Indian Population and to evaluate the performance of fasting plasma glucose (FPG) in screening and diagnosis of GDM.

\section{METHODS}

Consecutive pregnant women with singleton pregnancy at 24th to 28th week of gestation attending the ante-natal clinics in the Department of Gynaecology and Obstetrics, Santosh Hospital, Ghaziabad, for a period of one year, were recruited for the study. Women known to have preexisting diabetes were excluded from the study. Written consent was obtained from all the women and the study was approved by the Ethics Committee of the Santosh University.

At intake, a detailed history and clinical examination was taken which included, general information on demographic characteristics, socio-economic status, education level, obstetric history, family history of diabetes, height, and self-reported weight (before pregnancy). BMI was calculated as weight in kilograms divided by the square of height in meters.

Women were advised to come for testing after $>8 \mathrm{~h}$ overnight fast. Their blood samples were taken in fasting state and 1-h and 2-h after 75-g oral glucose load. Plasma glucose was estimated by glucose-oxidase-peroxidase (GOD-POD) technique.

The women were classified as GDM and non GDM, based on the IADPSG criteria [fasting plasma glucose (FPG) $\geq 92 \mathrm{mg} / \mathrm{dL}, 1$-h post-glucose $(\mathrm{PG})$ value $\geq 180$ $\mathrm{mg} / \mathrm{dL}$ and $2-\mathrm{h}$ PG value $\geq 153 \mathrm{mg} / \mathrm{dL}]$.) Women classified as GDM were referred to an endocrinologist and were assigned a special diet (treatment) and, if needed, medication.

Performance of the FPG value to screen for GDM was analysed based on the receiver operating characteristic (ROC) curve.

\section{Statistical analysis}

The continuous variables were expressed as mean and standard deviation (SD).The categorical variables were expressed as number and percentage. Student's t-test was used for the comparison of groups and $\mathrm{P}$ value $<0.05$ was considered significant. Receiver Operating Characteristic (ROC) analysis was used to evaluate the discriminatory power of FPG as screening test. By interpolation from the area under the curve, the point closest to the upper-left corner, which maximized sensitivity and specificity, was selected; this identified the highest number of subjects with or without a GDM. Data were analyzed using Medcalc (Version 12.6.0). 


\section{RESULTS}

A total of 450 pregnant women were recruited for the study out of which 417 women completed the study and their data were analysed.

The prevalence of GDM was $17.7 \%$ [95\% Confidence interval (CI) $21.4-14.1 \%$ ] using the IADPSG criteria. High Fasting Plasma Glucose (FPG) was seen in the 48(64.9\%) participants, high 1-h plasma glucose levels was revealed in $32(43.2 \%)$ of the participants, high 2 -h plasma glucose occurred in $21(28.4 \%)$ of the participants (Table 1 and Figure 1).

The 74 cases diagnosed as GDM were then categorized across seven groups based on the number of values over IADPSG thresholds: 1) FPG only (34 cases,45.9\%), 2) 1- h plasma glucose only (no cases, 3) 2-h plasma glucose only (3 cases,4.1\%), 4) FPG and 1-h plasma glucose (13 cases, 17.6\%), 5) FPG and 2-h plasma glucose (6, cases,8.1\%), 6) 1-h plasma glucose and 2-h plasma glucose (15 cases, $20.3 \%$ ), and 7) FPG and 1-h plasma glucose and 2-h plasma glucose (6 cases, $8.1 \%$ ).

Table 1: Prevalence of GDM by IADPSG criteria.

\begin{tabular}{|l|l|}
\hline Criteria & IADPSG n (\%) \\
\hline Number of GDM & $74(17.7 \%)$ \\
\hline Abnormal FPG alone & $48(64.9 \%)$ \\
\hline Abnormal 1-h PG alone & $32(43.2 \%)$ \\
\hline Abnormal 2-h PG alone & $21(28.4 \%)$ \\
\hline Any two abnormal values & $34(8.1 \%)$ \\
\hline All three abnormal values & $6(1.4 \%)$ \\
\hline
\end{tabular}

Table 2: Demographics summary.

\begin{tabular}{|c|c|c|c|c|}
\hline & GDM present & GDM not present & Total & P value \\
\hline n (Number of cases) & 74 & 343 & 417 & \\
\hline Age (mean \pm sd) & $26.4 \pm 3.6$ & $25.1 \pm 3.8$ & $26 \pm 3.9$ & 0.3 \\
\hline FPG (mean \pm sd) & $95.9(17.2)$ & 78.1(6.4) & $81.2(11.4)$ & 0.001 \\
\hline BMI (mean \pm sd) & $24.6 \pm 4.1$ & $23.8 \pm 3.7$ & $23.8 \pm 3.8$ & 0.66 \\
\hline \multicolumn{5}{|l|}{ Family History of Diabetes } \\
\hline Yes $\mathrm{n}(\%)$ & $8(10.8)$ & $8(2.3)$ & $16(3.8)$ & \multirow{2}{*}{0.003} \\
\hline No $n(\%)$ & $66(89.1)$ & $336(97.9)$ & $402(96.4)$ & \\
\hline Previous Spontaneous Abortion $\mathrm{n}(\%)$ & $21(28.3)$ & $119(34.6)$ & $140(33.5)$ & \multirow[b]{2}{*}{0.34} \\
\hline $\begin{array}{l}\text { No Previous Spontaneous Abortion } \\
\mathrm{n}(\%)\end{array}$ & $53(71.6)$ & $224(65.3)$ & $277(66.4)$ & \\
\hline Nullipara n(\%) & $31(41.8)$ & $127(37.0)$ & $211(50.5)$ & \\
\hline Multipara $(\%)$ & $43(58.1)$ & $216(62.9)$ & $6(1.4)$ & 0.43 \\
\hline \multicolumn{5}{|l|}{ Class } \\
\hline Upper $\mathrm{n}(\%)$ & $14(18.9)$ & $48(13.9)$ & $62(14.8)$ & \multirow{5}{*}{0.45} \\
\hline Upper Middle n(\%) & $24(32.4)$ & $94(27.4)$ & $118(28.2)$ & \\
\hline Upper Lower n(\%) & $2(2.7)$ & $14(4.08)$ & $16(3.8)$ & \\
\hline Lower Middle n $(\%)$ & $15(20.2)$ & $101(29.4)$ & $116(27.8)$ & \\
\hline Lower & $19(25.6)$ & $86(25.0)$ & $105(25.1)$ & \\
\hline
\end{tabular}

Table 3: Prevalence of GDM according to age of the subjects.

\begin{tabular}{|c|c|c|c|c|}
\hline $\begin{array}{l}\text { Age group } \\
\text { (years) }\end{array}$ & GDM & Non GDM & Total & P value \\
\hline$<20$ & 1 & 23 & 24 & \multirow{6}{*}{0.39} \\
\hline $21-25$ & 36 & 149 & 185 & \\
\hline $26-30$ & 25 & 127 & 152 & \\
\hline $31-35$ & 11 & 41 & 52 & \\
\hline$\geq 36$ & 1 & 3 & 4 & \\
\hline Total & 74 & 343 & 417 & \\
\hline
\end{tabular}

Main characteristics of pregnant women enrolled in the study are presented in Table 2. Out of 417 women in study population 52 women were in the age group of $\geq 30$ years; 12 women $(21.4 \%)$ had GDM as compared to $62(17 \%)$ women out of 365 women in the age group $\leq 30$ years. Prevalence of GDM was comparable between the age groups $(\mathrm{P}=0.39)$ (Table 3$)$.

Variables such as age and family history of diabetes were significantly different between the GDM and the nonGDM groups (Table 2). Gravida number, BMI and history of spontaneous abortion were not significantly different between the GDM and the non-GDM groups (Table 2). The FPG value (mean \pm SD) in women with GDM was $95.9 \pm 17.2$ and $78.1 \pm 6.4$ in women without GDM, a statistically significant difference $(\mathrm{p}=0.001)$. 
The receiver operating characteristic (ROC) curve (Figure 2) was drawn to determine the sensitivity and specificity of FPG in detecting GDM. The area under the ROC curve (AUC) of FPG to detect GDM was 0.856 (95\% CI 0.819 to 0.888 ). Values between 80 and 92 $\mathrm{mg} / \mathrm{dl}$ classified $54.7-11.5 \%$ of the women as having a positive test and were thus considered as potentially relevant cut-off points.

Table 4: GDM diagnosis by IADPSG criteria.

\begin{tabular}{|llll|}
\hline $\begin{array}{l}\text { FPG at or above the } \\
\text { threshold }\end{array}$ & $80 \mathrm{mg} / \mathrm{dl}$ & $\begin{array}{l}85 \\
\mathrm{mg} / \mathrm{dl}\end{array}$ & $92 \mathrm{mg} / \mathrm{dl}$ \\
\hline $\begin{array}{l}\text { No. of women at or } \\
\text { above the threshold } \\
\text { [n(\%)] }\end{array}$ & $\begin{array}{c}228 \\
(54.7)\end{array}$ & $\begin{array}{l}97 \\
(23.3)\end{array}$ & $\begin{array}{l}48 \\
(11.5)\end{array}$ \\
\hline $\begin{array}{l}\text { False negative rate } \\
(\%)\end{array}$ & 1.9 & 29.7 & 6.2 \\
\hline $\begin{array}{l}\text { Sensitivity to detect } \\
\text { GDM (\%) }\end{array}$ & 89.2 & 70.3 & 64.9 \\
\hline $\begin{array}{l}\text { PPV to detect GDM } \\
(\%)\end{array}$ & 28.9 & 52.5 & 100 \\
\hline $\begin{array}{l}\text { Positive likelihood } \\
\text { ratio }\end{array}$ & 1.89 & 5.16 & \\
\hline $\begin{array}{l}\text { No. of women below } \\
\text { the threshold } \\
\text { [n }(\%) \text { ] }\end{array}$ & 189 & 320 & 369 \\
\hline False positive rate $(\%)$ & 38.8 & 11.3 & 0.0 \\
\hline $\begin{array}{l}\text { Specificity to detect } \\
\text { GDM (\%) }\end{array}$ & 52.8 & 86.4 & 100 \\
\hline $\begin{array}{l}\text { NPV to detect GDM } \\
(\%)\end{array}$ & 95.8 & 93.1 & 92.9 \\
\hline $\begin{array}{l}\text { Negative likelihood } \\
\text { ratio }\end{array}$ & 0.20 & 0.34 & 0.35 \\
\hline
\end{tabular}

IADPSG: International Association of Diabetes and Pregnancy Study Groups.

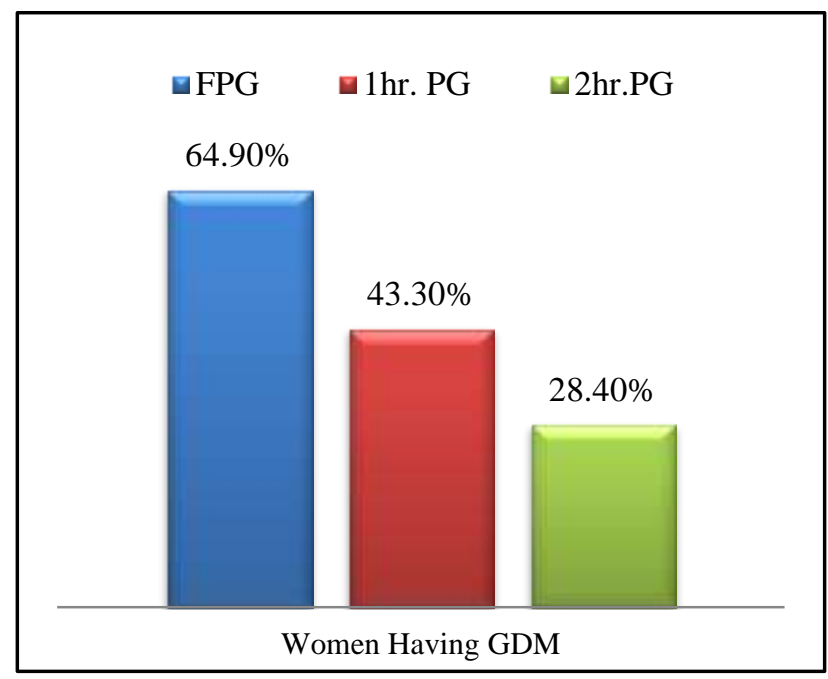

Figure 1: Diagnosis of GDM by IADPSG criteria.

A rule-in and rule-out algorithm was used for the FPG to predict GDM. Briefly, this approach involves considering two FPG cut- off values. The higher threshold, with an inherently increased specificity, rules in GDM; the lower threshold, with its innate increased sensitivity, rules out GDM. Women who have FPG values in between these two thresholds are indeterminate and would need the diagnostic OGTT. In this study, using the two-cut off approach, a higher FPG threshold of $\geq 92 \mathrm{mg} / \mathrm{dl}$ ruled in GDM in 48 (11.5\%) women with $100 \%$ specificity (Table 4). A lower FPG threshold of $4.4 \mathrm{mmol} / \mathrm{L}(80 \mathrm{mg} / \mathrm{dl})$ ruled out GDM in 189 (45.3\%) women at an acceptable sensitivity of $89.2 \%$; only 8 (1.9\%) women with GDM were misclassified as healthy.

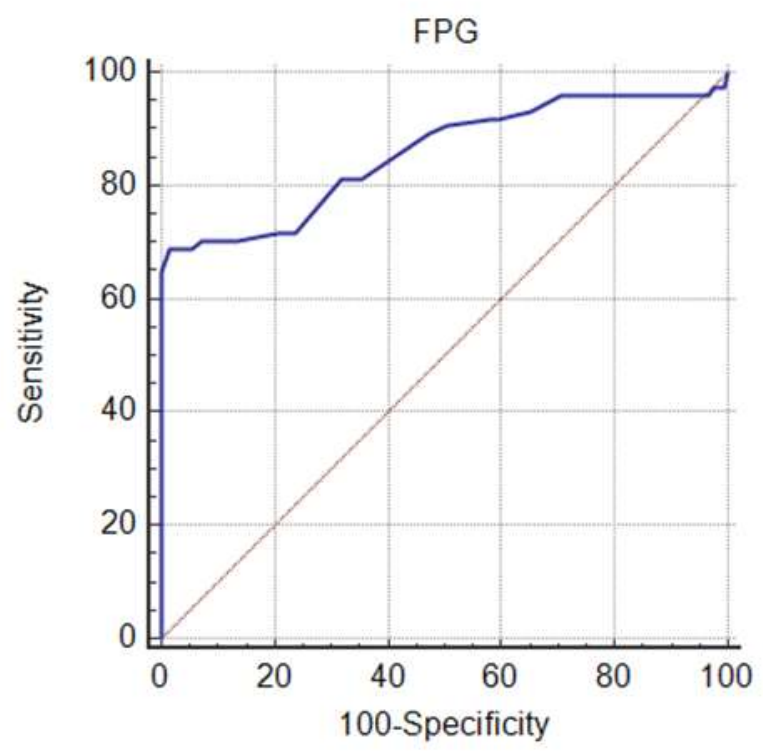

Figure 2: ROC curve of fasting plasma glucose using IADPSG criteria for diagnosing GDM.

An FPG cut-off value of $\geq 5.1 \mathrm{mmol} / 1$ (92 $\mathrm{mg} / \mathrm{dl})$ had sensitivity of $64.86 \%$ and specificity of $100.00 \%$ in diagnosing GDM. An FPG cut-off value of $\leq 4.4 \mathrm{mmol} / \mathrm{l}$ $(80 \mathrm{mg} / \mathrm{dl})$ had sensitivity of $89.19 \%$ and specificity of $52.77 \%$ in diagnosing GDM.

If $4.4 \mathrm{mmol} / \mathrm{L}$ were made the cut point to decide who should have the 75-g OGTT, then $56.8 \%$ (45.3\% with values <4.4 $\mathrm{mmol} / \mathrm{L}$ plus $11.5 \%$ with value >5.1 $\mathrm{mmol} / \mathrm{L}$ ) of pregnant women could avoid the 75 -g OGTT with the probability that $1.9 \%$ of patients with GDM may be missed.

\section{DISCUSSION}

The prevalence of GDM was $17.7 \%$ [95\% Confidence interval (CI) $21.4-14.1 \%$ ] using the IADPSG criteria, in our study population.

The frequency of GDM in our study population is similar to that of the HAPO study $(17.8 \%)$. Indian women were not represented in the HAPO cohort. Among the collaborating centres in the HAPO study, the prevalence rates of GDM differed widely, varying $9-25.5 \%$. $^{7}$ 
In an Indian study by Seshiah et al, on 1463 consecutive pregnant women, GDM was diagnosed in $14.6 \%$ of women by International Association Of The Diabetes And Pregnancy Study Group (IADPSG) criteria and is quite high as compared to previous studies. ${ }^{11}$

In a retrospective analysis of South Asian women in the United Arab Emirates, Agarwal et al. also reported a very high prevalence of GDM $(38 \%)$ by the IADPSG criteria when compared with the ADA 2010 criteria (13\%). ${ }^{9}$

In the present study using the IADPSG diagnostic criteria, $64.9 \%$ (11.5\% of the total population)of GDM was diagnosed by an FPG $\geq 5.1 \mathrm{mmol} / \mathrm{L}(92 \mathrm{mg} / \mathrm{dl})$, whereas $51 \%$ and $40 \%$ of GDM was diagnosed by an FPG $>5.1 \mathrm{mmol} / \mathrm{L}(92 \mathrm{mg} / \mathrm{dl})$, in the HAPO study and that of Mahdavian et al, respectively. ${ }^{6,12}$

In deciding if the pregnant woman should continue with her OGTT in this study, using the two cut-off approach, a higher FPG threshold of $\geq 5 \mathrm{mmol} / \mathrm{L}$ ruled in GDM in 48 $(11.5 \%)$ women with $100 \%$ specificity (Table 4$)$. A lower FPG threshold of $<4.4 \mathrm{mmol} / \mathrm{L}$ ruled out GDM in 189 $(45.3 \%)$ women at an acceptable sensitivity of $89.2 \%$; only $8(1.9 \%)$ women with GDM were misclassified as healthy. In the Hyperglycemia and Adverse Pregnancy Outcome Study, risks of adverse outcomes were low when the FPG was $\leq 4.4 \mathrm{mmol} / \mathrm{L} .^{5}$

If $4.4 \mathrm{mmol} / \mathrm{L}$ were made the cut point to decide who should have the 75-g OGTT, then in our study, $56.8 \%$ (45.3\% with values $<4.4 \mathrm{mmol} / \mathrm{L}$ plus $11.5 \%$ with value $>5.1 \mathrm{mmol} / \mathrm{L}$ ) of pregnant women could avoid the $75-\mathrm{g}$ OGTT with the probability that $1.9 \%$ of patients with GDM may be missed.

Among the studies performed for investigating FPG as a means of orienting further testing when GDM is based on IADPSG criteria, Agarwal et al. found an AUC of 0.907 (95\% CI 0.899-0.914) for FPG as a test to direct further testing for the detection of GDM. The authors also recommended a cut-off point of $4.4 \mathrm{mmol} / \mathrm{l}(80 \mathrm{mg} / \mathrm{dl})$, which provided a sensitivity of $95.4 \%$ and specificity of $32.0 \%{ }^{9}$

In our study the area under the ROC curve of FPG to detect GDM was 0.856 (95\% CI 0.819 to 0.888 ). Values between 80 and $92 \mathrm{mg} / \mathrm{dl}$ classified $54.7-11.5 \%$ of the women as having a positive test and were thus considered as potentially relevant cut-off points.

In the Agarwal et al study, $4.6 \%$ of GDM cases would have been missed by not performing OGTT for women whose FPG $<4.4 \mathrm{mmol} / \mathrm{l}(80 \mathrm{mg} / \mathrm{dl}){ }^{9}{ }^{9}$ In another study by Mahdavian et al. 23\% of women with GDM would have been misclassified as healthy by not performing OGTT for women whose FPG $<4.4 \mathrm{mmol} / \mathrm{l}(80 \mathrm{mg} / \mathrm{dl}){ }^{12}$ Our study results are similar to the study by Agarwal et al. and only $1.9 \%$ of GDM cases would have been missed by not performing OGTT for women whose FPG $<4.4$ $\mathrm{mmol} / \mathrm{l}(80 \mathrm{mg} / \mathrm{dl})$.

Another recent study Zhu B et al, from China also suggested the FPG cut-off value of $4.4 \mathrm{mmol} / \mathrm{l}$, finding a sensitivity of $87.8 \%$ and specificity of $45.8 \%$, although the AUC found for FPG was lower, 0.836 (95\% CI $0.829-0.843) .{ }^{13}$ In their study FPG cut off value of 5.1 $\mathrm{mmol} / \mathrm{L}$ identified $12.1 \%$ pregnant women with GDM. FPG cut off value of $4.4 \mathrm{mmol} / \mathrm{L}$ ruled out GDM in $38.2 \%$ women. With use of this cut off point, $12.2 \%$ of patients with mild GDM will be missed. The positive predictive value was 0.322 , and the negative predictive value was $0.928 .^{13}$

In our present study FPG cut off value of $5.1 \mathrm{mmol} / \mathrm{L}$ identified $48(11.5 \%)$ pregnant women with GDM. The positive predictive value is 0.289 , and the negative predictive value is 0.958 and is similar to the study by Zhu et al. ${ }^{13}$ Women with FPG values between 4.4 and $5.1 \mathrm{mmol} / \mathrm{L}$ require a $75-\mathrm{g} 2$-h OGTT to confirm or rule out GDM.

In a recent study from Pondicherry in South India conducted at a government hospital, the prevalence of GDM was as high as $27.3 \%$ as per the IADPSG criteria and FPG alone detected $63.9 \%$ of GDM cases. ${ }^{14}$ Though the prevalence of GDM was not as high but the detection rate by FPG alone was similar in our study. GDM was diagnosed in $41.9 \%$, $(36.6-47.2 \%, 95 \% \mathrm{CI})$ ] women in a study from Lucknow. ${ }^{15}$ Also, of all the GDM women diagnosed by the IADPSG criteria, $91.4 \%$ had abnormal FPG. ${ }^{15}$

In light of the recent studies coming from Indian population Mohan et al have recommended that universal screening for GDM is necessary amongst Indians and at the time of the first registration. ${ }^{16}$ Fasting plasma glucose estimation should be done in all pregnant women. In order to obtain international standardization, they recommended that, wherever possible, a single-step fasting OGTT using $75 \mathrm{~g}$ glucose and the IADPSG criteria be used, with the two-step procedure remaining a viable option. ${ }^{16}$

Considering laboratory costs and workload, making use of an initial FPG, as a screening test for GDM, is an advantageous approach, both effective and efficient, and will be proportionate to expected risk.

The limitation of the present study is that the number of cases is less. Second, as this was a hospital-based study in a semi-urban setting, the results may not be applicable to the general population. Therefore, studies recruiting larger number of pregnant women, from rural and urban settings, are require finding out the prevalence of GDM. The utility of FPG as a screening test for GDM in the same population, as suggested in the present study, should also be tested. 


\section{CONCLUSION}

FPG at 24-28 weeks' gestation could be used as a screening test to identify GDM patients in low-resource regions. Women with an FPG between $\geq 80 \mathrm{mg} / \mathrm{dL}$ and $\leq 92 \mathrm{mg} / \mathrm{dL}$ would require a 75-g OGTT to diagnose GDM. This would help to avoid approximately one-half $(53.6 \%)$ of the formal 75-g OGTTs in India.

\section{ACKNOWLEDGEMENTS}

Authors would like to thanks all the members of Santosh University for their help and co-operation. We would also like to thank all the women who participated in our study.

Funding: No funding sources

Conflict of interest: None declared

Ethical approval: The study was approved by the Institutional Ethics Committee of Santosh University

\section{REFERENCES}

1. American Diabetic Association. Classification and diagnosis of diabetes mellitus. Diabetes Care. 2015;38 (Suppl 1):S8-16.

2. Damm P. Future risk of diabetes in mother and child after gestational diabetes mellitus. Int $\mathrm{J}$ Gynaecol Obstet. 2009;104(Suppl. 1):S25=6

3. Crowther CA, Hiller JE, Moss JR, McPhee AJ, Jeffries WS, Robinson JS. Australian Carbohydrate Intolerance Study in Pregnant Women (ACHOIS) Trial Group. Effect of treatment of gestational diabetes mellitus on pregnancy outcomes. N Engl J Med. 2005;352:2477-86.

4. Landon MB, Spong CY, Thom E, Carpenter MW, Ramin SM, Casey B, et al. Eunice Kennedy Shriver National Institute of Child Health and Human Development Maternal-Fetal Medicine Units Network. A multicenter, randomized trial of treatment for mild gestational diabetes. $\mathrm{N}$ Engl J Med. 2009;361:1339-48.

5. Metzger BE, Lowe LP,Dyer AR, et al; HAPO Study Cooperative Research Group. Hyperglycemia and adverse pregnancy outcomes. $\mathrm{N}$ Engl J Med. 2008;358:1991-2002

6. International Association of Diabetes and Pregnancy Study Groups Consensus Panel, Metzger BE, Gabbe $\mathrm{SG}$, Persson B, et al. International association of diabetes and pregnancy study groups recommendations on the diagnosis and classification of hyperglycemia in pregnancy. Diabetes Care. 2010;33(3):676-82.
7. Sacks DA, Hadden DR, Maresh M. Frequency of gestational diabetes mellitus at collaborating centers based on IADPSG consensus panel-recommended criteria: the Hyperglycemia and Adverse Pregnancy Outcome (HAPO) Study. Diabetes Care. 2012;35:526-8.

8. Mohan V, Mahalakshmi MM, Bhavadharini B, Maheswari K, Kalaiyarasi G, Anjana RM, et al. Comparison of screening for gestational diabetes mellitus by oral glucose tolerance tests done in the non-fasting (random) and fasting states. Acta Diabetol. 2014;51:1007-13.

9. Agarwal MM, Dhatt GS, Shah SM. Gestational diabetes mellitus: simplifying the international association of diabetes and pregnancy diagnostic algorithm using fasting plasma glucose. Diabetes Care. 2010;33:2018-20.

10. Donovan L, Hartling L, Muise M, Guthrie A, Vandermeer B, Dryden DM. Screening tests for gestational diabetes: a systematic review for the U.S. Preventive Services Task Force. Ann Intern Med.. 2013;159:115-22.

11. Seshiah V, Balaji V, Shah SN. Diagnosis of gestational diabetes mellitus in the community. J Assoc Physicians India. 2012;16:15-7.

12. Mahdavian M, Hivert MF, Baillargeon JP, Menard J, Ouellet A, Ardilouze JL. Gestational diabetes mellitus: simplifying the international association of diabetes and pregnancy diagnostic algorithm using fasting plasma glucose: comment on Agarwal, Dhatt, and Shah. Diabetes Care. 2010;33:145.

13. Zhu W, Fan L, Yang H, Kong L, Su S, Wang Z, et al. Fasting plasma glucose at 24-28 weeks to screen for gestational diabetes mellitus: new evidence from China. Diabetes Care. 2013;36:2038-40.

14. Nayak PK, Mitra S, Sahoo JP, Daniel M, Mathew A, Padma A. Feto-maternal outcomes in women with and without gestational diabetes mellitus according to the international association of diabetes and pregnancy study groups (IADPSG) diagnostic criteria. Diabetes Metab Syndr. 2013;7:206-9.

15. Gopalakrishnan V, Singh R, Pradeep Y, Kapoor D, Rani AK, Pradhan S, et al. Evaluation of the prevalence of gestational diabetes mellitus in North Indians using the International Association of Diabetes and Pregnancy Study groups (IADPSG) criteria. J Postgrad Med. 2015;61:155-8.

16. Mohan V, Usha S, Uma R. Screening for gestational diabetes in India: Where do we stand? J Postgrad Med. 2015;61:151-4.

Cite this article as: Sharma A, Agrawal A, Goel M, Gupta M. Utility of fasting plasma glucose test as screening tool for gestational diabetes mellitus based on international association of the diabetes and pregnancy study group criteria. Int $\mathrm{J}$ Reprod Contracept Obstet Gynecol 2016;5:2005-10. 